\title{
Transforming growth factor- $\beta$-mediated signaling in T lymphocytes impacts on prostate-specific immunity and early prostate tumor progression
}

\author{
Kerrilyn R Diener ${ }^{1,2}$, Anthony E Woods ${ }^{2}$, Jim Manavis ${ }^{3,4}$, Michael P Brown ${ }^{1,5,6,7}$ and John D Hayball, 2,6,7
}

T cells are in general tolerant of prostate-specific tumor antigens. That prostate tumor tissue makes transforming growth factor- $\beta(\operatorname{TGF} \beta)$ is thought to play a role in the induction of T-cell tolerance within the host and to contribute to tumor progression itself. Here we sought to investigate the influence of TGF $\beta$ signaling on prostate antigen-specific T-cell responses as well as prostate tumorogenesis in an autochthonous murine model of the disease. The response of naive and activated ovalbumin (OVA) antigen-specific T cells, which had been rendered incapable of responding to TGF $\beta$ through T-cell-specific transgenic expression of a dominant-negative variant of the TGF $\beta$ receptor II (dnTGFRII), was analyzed after adoptive transfer into prostate OVA-expressing transgenic (POET) mice. The role of TGF $\beta$ signaling in endogenous T cells in mice, which spontaneously form tumors, was also assessed by monitoring prostate tumor formation and progression in F1 progeny of productive matings between transgenic adenocarcinoma of the mouse prostate (TRAMP) and dnTGFRII mice. TGF $\beta$-resistant CD8 ${ }^{+}$T cells proliferated more and produced IFN $\gamma$ more readily after OVA stimulation in vitro. OVA-specific T cells did not damage the prostate gland of POET mice irrespective of TGF $\beta$ responsiveness. However, ex vivo activation facilitated entry of TGF $\beta$-insensitive T cells into the prostate and was associated with prostate tissue damage. Early tumor progression was delayed in TRAMP mice that carried endogenous TGF $\beta$-insensitive T cells. Together, these results suggest that TGF $\beta$-signaling represses CD8 ${ }^{+} \mathrm{T}^{\text {-cell }}$ responses to a prostate-specific antigen. TGF $\beta$-mediated repression of T-cell function may include production of IFN $\gamma$, which is known to contribute to tumor immunosurveillance.

Laboratory Investigation (2009) 89, 142-151; doi:10.1038/labinvest.2008.123; published online 15 December 2008

KEYWORDS: adoptive transfer; OT-I T cells; CD4-dnTGFRIl; prostate cancer

Prostate cancer is the most frequently diagnosed nonskin cancer among men in part because of increased prostatespecific antigen screening. ${ }^{1}$ Most newly diagnosed patients present with localized disease, which is often curable by surgical resection or external beam radiotherapy. However, such treatments do not apply to patients diagnosed with recurrent or metastatic disease. Although survival can be prolonged with androgen-deprivation therapy, ultimately all patients succumb to fatal castration-refractory disease. Accordingly, there is great impetus to develop new therapeutic strategies to treat this disease. The discovery of several prostate tumor-specific antigens combined with the nonvital nature of the prostate gland, has led to the development of novel passive and active immunotherapeutic approaches (reviewed in Basler and Groettrup ${ }^{2}$ ). However, attempts to validate these approaches clinically has produced only a modest induction in tumor-specific T-cell responses in some patients, and few studies demonstrate any impact on important clinical outcomes such as tumor regression and patient survival. ${ }^{2-5}$

The failure to induce robust antitumor clinical responses may be in part because of suboptimal antigen presentation, the production of immunosuppressive cytokines, T-cell dysfunction and induction of regulatory T-cell populations. ${ }^{6-8}$ We have previously demonstrated in mice that transgenic $T$ cells specific for a nominal prostate-specific antigen

\footnotetext{
${ }^{1}$ Experimental Therapeutics Laboratory, Hanson Institute, Adelaide, SA, Australia; ${ }^{2}$ Sansom Institute, University of South Australia, Adelaide, SA, Australia; ${ }^{3}$ Centre for Neurological Diseases, The Hanson Institute, Adelaide, SA, Australia; ${ }^{4}$ Department of Neuropathology, SA Pathology, Adelaide, SA, Australia; ${ }^{5}$ Department of Medical Oncology, Royal Adelaide Hospital, Adelaide, SA, Australia and ${ }^{6}$ School of Medicine, The University of Adelaide, Adelaide, SA, Australia

Correspondence: Dr JD Hayball, Bsc, DIC, PhD, Sansom Institute, The University of South Australia, North Tce, Adelaide, SA 5000, Australia.

E-mail: john.hayball@unisa.edu.au

${ }^{7}$ These authors contributed equally to this work.

Received 13 May 2008; revised 19 September 2008; accepted 9 October 2008
} 
proliferate after recognition of this antigen within the prostate-draining lymph nodes. However, despite in vivo or ex vivo activation, only a transient presence of activated prostate antigen-specific $\mathrm{T}$ cells was detected within the prostate gland itself, and no evidence of tissue pathology was evident. ${ }^{9}$ Similarly, in a different murine model system, prostate antigen-specific $\mathrm{T}$ cells were found within malignant prostate tissue, but despite effective priming, these cells were subsequently rendered anergic. ${ }^{10}$ Together, these results suggest that an immunosuppressive microenvironment exists within the prostate gland.

Testosterone and its metabolite dihydrotestosterone are essential for the healthy development and function of the prostate, ${ }^{11}$ and these androgens are regulated by the activity of growth factors, in particular, transforming growth factor- $\beta$ $(\mathrm{TGF} \beta) .{ }^{12,13}$ Transforming growth factor- $\beta$ is a potent immunoregulatory cytokine that is essential for maintaining immunological tolerance. ${ }^{14,15}$ Depending on the cellular context, TGF $\beta$ also contributes significantly to the initiation and resolution of inflammation by influencing the chemotaxis, activation and survival of both innate and adaptive immune cells in inflamed tissues (reviewed in Li et al ${ }^{16}$ ). In the prostate, TGF $\beta$ stimulates cell differentiation and inhibits epithelial cell proliferation by inducing cellular apoptosis and maintaining dormancy in prostatic stem cells. $^{12,13,17,18}$ However, TGF $\beta$ also plays a complex role in the regulation of prostate cancer growth. ${ }^{19}$ High levels of TGF $\beta 1$ have been found in serum and tumors of patients with prostate cancer ${ }^{20-22}$ and this is associated with more aggressive tumors, which exhibit increased angiogenic and metastatic potential. ${ }^{23,24}$ A concomitant loss of TGF $\beta$ receptor expression in malignant tissue increases resistance to the antiproliferative and pro-apoptotic effects of TGF $\beta 1,{ }^{25}$ and is also associated with a poor prognosis. ${ }^{26,27}$ Furthermore, TGF $\beta 1$ secreted by tumors can function as a potent immunosuppressive agent, capable of inhibiting the response of tumor-specific lymphocytes ${ }^{19,28}$ and thereby facilitating tumor growth by down-modulating host antitumor immunity. ${ }^{29}$

To further our understanding of prostate-antigen-specific immune responses and the relationship between TGF $\beta$ production and immune outcomes, we used transgenic mice engineered to express the nominal antigen, chicken ovalbumin (OVA), under control of a prostate-specific promoter, ${ }^{30}$ into which were adoptively transferred transgenic OVA-specific $\mathrm{CD}^{+}{ }^{+} \mathrm{T}$ cells made insensitive to the effects of TGF $\beta$ signaling. Our results indicate that, after adoptive transfer and cognate antigen recognition, these $\mathrm{T}$ cells proliferate more vigorously than wild-type transgenic $\mathrm{T}$ cells. Furthermore, once activated, TGF $\beta$-resistant $\mathrm{T}$ cells infiltrate the prostate gland when they are associated with tissue injury. Finally, we show that TGF $\beta$ signaling in the endogenous $\mathrm{CD} 8{ }^{+} \mathrm{T}$-cell compartment promotes the early progression of prostate cancer in transgenic adenocarcinoma of the mouse prostate (TRAMP) mice, which represents an autochthonous model of the disease.

\section{MATERIALS AND METHODS}

\section{Mice}

Nontransgenic C57BL/6J (B6) mice were purchased from Laboratory Animal Services (Adelaide, SA, Australia). OT-I T-cell receptor transgenic mice, ${ }^{31}$ which have $\mathrm{CD} 8{ }^{+} \mathrm{T}$ cells that recognize a chicken OVA peptide $\left(\mathrm{OVA}_{257-264}\right)$ in the context of $\mathrm{H} 2-\mathrm{K}^{\mathrm{b}}$ were kindly provided by Prof. WR Heath (Walter and Eliza Hall Institute of Medical Research, Melbourne, VIC, Australia). The prostate OVA-expressing transgenic (POET) mice, ${ }^{30}$ express membrane-bound OVA at high levels in the ventral and dorsolateral prostate lobes under the control of the $\mathrm{ARR}_{2} \mathrm{~PB}$ promoter and were generously provided by Prof. TL Ratliff (University of Iowa City, IA, USA). Homozygous TRAMP ${ }^{32}$ mice are a line in which the prostate-specific rat probasin promoter drives expression of the SV40 large tumor antigen-coding region specifically within the prostate, and were kindly obtained from Dr M. Grossmann (Mayo Clinic, Rochester, MN, USA). Transgenic dominant-negative TGF $\beta$ receptor II (dnTGFRII) ${ }^{+1-}$ mice express a dominant-negative TGF $\beta$ receptor type II under the control of a CD4 promotor construct lacking the CD8 silencer and thus allowing expression of the transgene in both $\mathrm{CD}^{+}$and $\mathrm{CD}^{+}{ }^{+} \mathrm{T}_{\text {cells. }}{ }^{33}$ These mice were kindly provided by Prof. RA Flavell (Yale University School of Medicine and Howard Hughes Medical Institute, New Haven, CT, USA) and were maintained as a heterozygote line. TGF $\beta$-insensitive OT-I mice and TGF $\beta$-insensitive TRAMP mice were generated as F1 progeny from successful pairings of CD4-dnTGFRII $^{+/-}$and OT-I or TRAMP mice, respectively. Owing to the occurrence of an autoimmune phenotype in aging CD4-dnTGFRII ${ }^{+/-}$mice, these mice and all F1 progeny were administered broad-range antibiotics ad libitum via the drinking water.

\section{Antibodies and Reagents}

Synthetic chicken OVA peptide $\mathrm{OVA}_{257-264}$ (SIINFEKL) was synthesized on an ABI 431A peptide synthesizer using standard Fmoc chemistry. PE-conjugated CD8, IFN $\gamma$ and IL2; CyChrome-conjugated CD8; biotinylated CD49d, CD45RB, CD44, CD62l, CD25, CD69 and CD11a; and CyChromeconjugated streptavidin were all purchased from Pharmingen (BD Biosciences).

\section{Preparation of CFSE-Labeled OT-I T Cells}

Single cell suspensions were prepared from pooled major lymph node groups from TGF $\beta$-insensitive or control OT-I TCR Tg mice. 5 (and 6)-Carboxyfluorescein diacetate succinimidyl ester (CFSE; Molecular Probes, Invitrogen, Mount Waverley, Australia) labeling was performed as previously described. ${ }^{34}$ Briefly, cell populations were resuspended in PBS at $10^{7}$ cells $/ \mathrm{ml}$ with $0.1 \mu \mathrm{l}$ of CFSE stock solution $(5 \mathrm{mM}$ in DMSO) added per $\mathrm{ml}$ of cells and incubated for $10 \mathrm{~min}$ at $37^{\circ} \mathrm{C}$. Labeled cells were washed twice in PBS and analyzed by flow cytometry for at least a four-decade increase in 
mean fluorescence intensity over unlabeled cells before being utilized in in vitro or in vivo proliferation assays.

\section{Preparation of Ex Vivo- Activated OT-I T Cells}

Splenocyte cell suspensions $\left(10 \times 10^{6}\right.$ cells $\left./ \mathrm{ml}\right)$ were prepared from B6 mice and incubated with $\mathrm{OVA}_{257-264}$ peptide (SIINFEKL, $1 \mu \mathrm{M}$ ) for $3 \mathrm{~h}$ in RPMI culture medium (CM) supplemented with $10 \%$ FCS, $2 \mathrm{mM}$ glutamine, $20 \mathrm{mM}$ HEPES, $5 \times 10^{-5} \mathrm{M} 2$-ME and $50 \mu \mathrm{g} / \mathrm{ml}$ gentamycin. Cells were then recovered, washed three times in $\mathrm{CM}$ and resuspended at $2 \times 10^{6}$ cells $/ \mathrm{ml}$ in CM. Single cell suspensions $\left(2 \times 10^{6}\right.$ cells $/ \mathrm{ml}$ in $\left.\mathrm{CM}\right)$ were prepared from pooled major LN groups obtained from TGF $\beta$-insensitive or control OT-I TCR Tg mice. Equal numbers of peptide-loaded splenocytes and lymph node cells were incubated together for 2 days at $37^{\circ} \mathrm{C}$. Cultures were collected, layered over Lymphoprep (Nycomed, Zurich, Switzerland) gradient and spun to recover the activated viable cell population. These cells were then washed twice in $\mathrm{CM}$ and passed through a $70 \mu \mathrm{M}$ nylon strainer to remove any particulates before adoptive transfer into recipient mice.

\section{In Vitro Proliferation Assays}

B6 splenocytes were OVA peptide pulsed as described above, washed in CM and irradiated (15 Gy) to prevent proliferation. Following three washes in CM, splenocytes were mixed with CFSE-labeled TGF $\beta$-insensitive or control OT-I T cells at an equal ratio and placed into culture with $10 \mathrm{U} / \mathrm{ml}$ IL-2 at $37^{\circ} \mathrm{C}$ in $5 \% \mathrm{CO}_{2}$ in air. At $0,1,2,3$ and 4 days, a portion of cells were removed, stained for the expression of CD8 and split into nine tubes to allow for individual staining of activation markers and intracellular cytokine expression. Cells were then analyzed by three-color flow cytometry.

\section{Adoptive Transfer of Transgenic T Cells}

Groups of POET mice received filtered naive CFSE-labeled TGF $\beta$-insensitive or control OT-I T cells $\left(10^{7}\right)$ via the tail vein. At days 2, 3 and 4, cell populations recovered from the prostate-draining lymph nodes were incubated with antiCD8 antibodies, and analyzed by two-color flow cytometry. The extent of cellular proliferation of fluorescent adoptively transferred $\mathrm{T}$ cells was measured as the proliferative index (PI) as previously described, ${ }^{35}$ and is a direct measurement of the number of cells retrieved from each mouse for each cell put into the model system, with a $\mathrm{PI}=1$ indicating no proliferation. In some experiments, recipient mice received unlabeled naive or ex vivo-activated TGF $\beta$-insensitive OT-I or control OT-I cells $\left(10^{7}\right)$ via the tail vein. In some cases, prostate-derived single cell suspension were prepared at day 5 , stained with anti-CD8 and anti-V $\beta 5.1 / 5.2$ antibodies and analyzed by two-color flow cytometry. In other cases, prostates were removed 10 days post-adoptive transfer and processed for histological assessment by hematoxylin and eosin (H\&E) staining.

\section{Histopathologic Analysis}

The ventral lobe was dissected from the prostate with the removed tissue fixed in 10\% neutral-buffered formalin, and processed and embedded in paraffin using standard techniques. Sections $(5 \mu \mathrm{M})$ were subsequently cut from paraffinembedded tissue and stained with H\&E for histopathologic analysis. Scoring of prostate sections was performed blindly by pathologist (AEW) using a standardized grading system. ${ }^{36}$ Briefly, score criteria were as follows: 1, normal epithelium; 2, early signs of prostatic intraepithelial neoplasia (PIN) with tufting of the epithelium and increased nucleus:cytoplasm ratio; 3, more advanced PIN with noted cribiform structures and an increase in mitotic and/or apoptotic figures; 4, the loss of interductal spaces and the invasion of basement membranes; 5 , total loss of ductal lumens with evidence of adenocarcinoma and 6 , observed sheets of anaplastic cells. ${ }^{37}$

\section{Immunohistochemistry}

Formalin-fixed, paraffin-embedded tissue sections were stained with a CD3 polyclonal antibody (Dako, USA; cat no. A0452), using a standard streptavidin-biotinylated immunoperoxidase methodology. In brief, sections were dewaxed using xylene, and rehydrated through alcohols. Antigen retrieval was performed using Target retrieval buffer (Dako; cat no. S1699) in a microwave oven. Slides were allowed to cool and washed twice in PBS ( $\mathrm{pH}$ 7.4) before being transferred to a $0.025 \%$ Trypsin solution for $3 \mathrm{~min}$. The slides were again washed in PBS and then endogenous peroxide activity was quenched. Nonspecific proteins were blocked using normal goat serum for $20 \mathrm{~min}$. The CD3 antibody was then applied at a dilution of 1:6000 at room temperature overnight. The following day, the sections were washed in PBS and a biotinylated goat anti-rabbit secondary (Vector labs, USA; cat no. BA-1000) was applied for $60 \mathrm{~min}$. Following a PBS wash, the slides were incubated for $15 \mathrm{~min}$ with a streptavidin-conjugated peroxidase tertiary (Pierce, USA; cat no. 21127). The sections were then visualized using DAB, washed, counterstained with Hematoxylin, dehydrated, cleared and then mounted.

Figure 1 TGF $\beta$-insensitive OT-I T cells proliferate faster and produce more IFN $\gamma$ than OT-I T cells in response to cognate antigen. Single cell suspensions of pooled lymph nodes from dnTGFRIIXOT-I or OT-I mice were CFSE-labeled and incubated in vitro with SIINFEKL-pulsed B6 splenocytes. At 0, 1, 2, 3 and 4 days post-stimulation, a portion of the cells was removed, stained with anti-CD8 antibody and (a), analyzed by two-color flow cytometry to generate histograms of $\mathrm{CD}^{+}$cells depicting CFSE intensity over time with proliferative index determined using WEASEL version 2 software (Cytometry Lab, WEHI, Melbourne, Australia), or (b), further stained with either CD49d, CD45RB, CD44, CD62 L, CD25, CD69, CD11a, IFN $\gamma$ or IL-2 expression. Three-color flow cytometric analysis was subsequently performed on labeled dnTGFRIIxOT-I (black squares) and OT-I (white squares) cell populations with graphs depicting mean fluorescence intensity (MFI) of surface activation markers, or percent of $\mathrm{CD}^{+}$cells-expressing IFN $\gamma$ or IL-2 over time shown. Results are representative of two experiments. 
a Time in culture (days)
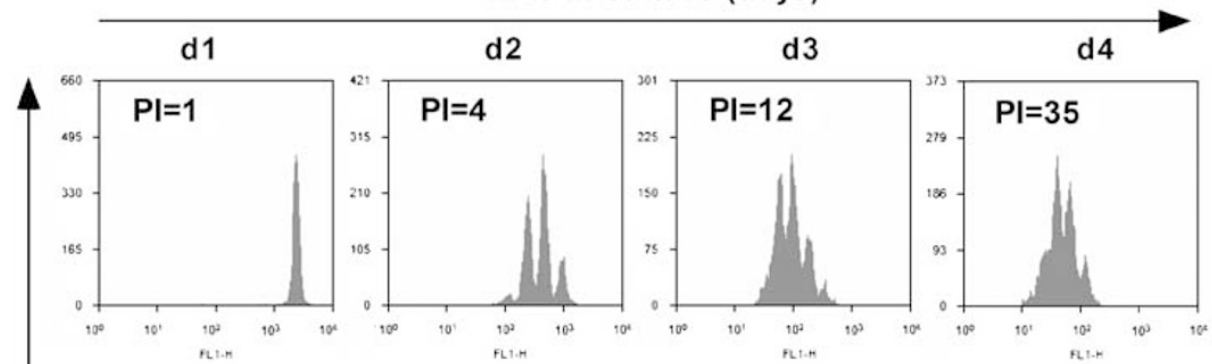

OT-I
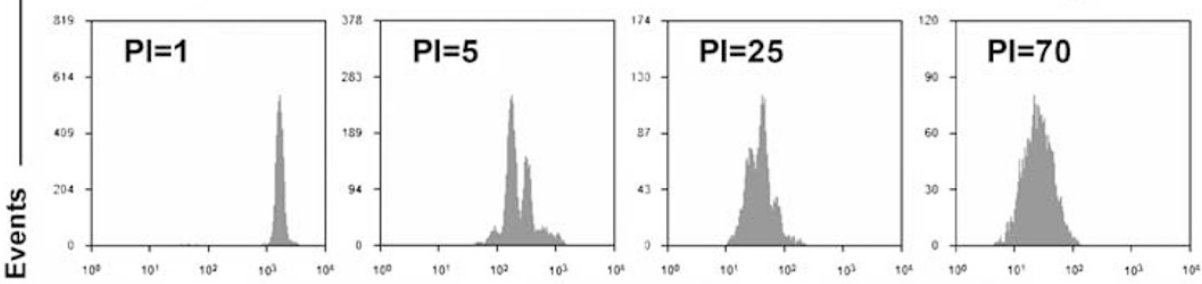

dnTGFRIIxOT-I

CFSE
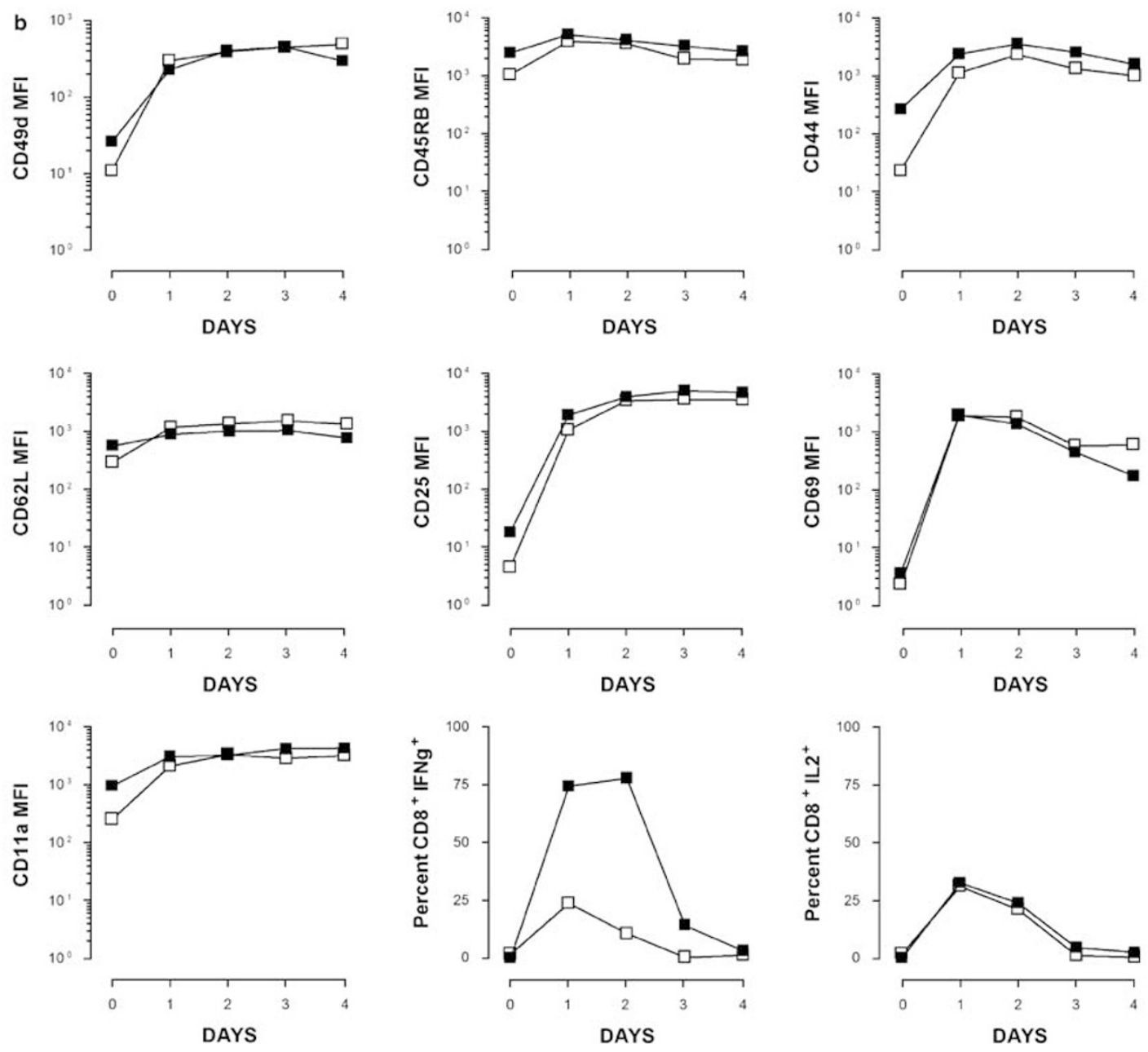


\section{RESULTS \\ Tgf $\beta$ Inhibited Antigen-Dependent Proliferation and IFN $\gamma$ Production Among CD8 ${ }^{+} \mathbf{T}$ Cells In Vitro}

To evaluate the effect that a CD8 ${ }^{+}$T-cell-specific lesion in TGFRII-mediated signaling had on cognate antigen recognition, we crossed OT-I TCR transgenic mice with CD4-dnTGFRII $^{+/-}$(dnTGFRII) mice to generate F1 progeny in which some mice contained OT-I T cells that were insensitive to exogenous TGF $\beta$. Lymph node preparations from these mice were stained with CFSE and stimulated in culture with OVA peptide-pulsed and irradiated syngeneic splenocytes, with the extent of T-cell proliferation assessed each day thereafter and compared to normal OT-I T cells. Our results indicated that normal and TGF $\beta$-insensitive OT-I $\mathrm{CD}^{+} \mathrm{T}$ cells responded vigorously to cognate antigen. However, by comparing the kinetic CFSE division profiles of each population, it was apparent that TGF $\beta$-insensitive OT-I $\mathrm{T}$ cells divided faster than normal OT-I T cells, culminating in a PI of 70 for TGF $\beta$-insensitive T cells, a much greater expansion than that observed for normal OT-I T cells $(\mathrm{PI}=35)$ at day 4 post-antigen challenge (Figure 1a).

To determine whether the difference in proliferative responses correlated with a differential expression of T-cell surface activation markers and cytokine production, naive TGF $\beta$-insensitive and normal OT-I T cells were again stimulated in vitro and analyzed daily for 4 days. Similar kinetic alterations in expression levels of the early activation markers CD69 and CD25, the homing receptors CD49d and CD11a, and memory phenotype markers, CD45RB, CD44 and CD62 L were observed in both TGF $\beta$-insensitive and normal OT-I T cells (Figure 1b), as well as comparable IL-2 production. However, the proportion of IFN $\gamma$-expressing OT-I T cells increased dramatically if TGF $\beta$ signaling was deficient in comparison to normal $\mathrm{T}$ cells ( 75 versus $25 \%$, on day 1 ), and peaked 1-2 days post-antigen recognition before declining.

\section{The Antiproliferative Effects of TGF $\beta$ Extended to Antigen Recognition by CD8 ${ }^{+} \mathrm{T}$ Cells In Vivo and Ex Vivo Activation of TGF $\beta$-Insensitive CD8 ${ }^{+}$T Cells was Required to Mediate Antigen-Dependent Prostate Tissue Damage}

To determine if $\mathrm{CD}^{+}{ }^{+}$T-cell resistance to TGF $\beta$ signaling was retained after antigen-specific T-cell activation in vivo, we used an adoptive transfer model in which CFSE-labeled T cells were introduced into POET mice. Sexually mature POET mice express high levels of OVA protein in prostate tissue, and OVA-derived, MHC class I-restricted peptide can be detected in the prostate-draining lymph nodes using proliferation of OT-I T cells as an indicator. ${ }^{30}$ CFSE-labeled TGF $\beta$-insensitive or normal OT-I T cells were adoptively transferred to recipient POET mice and at 2, 3 and 4 days post-transfer, the proliferative response of TGF $\beta$-insensitive and normal OT-I T cells recovered from the prostatedraining lymph nodes was assessed. All recipient POET mice recorded a PI $>1$, indicating that both types of OT-I T cells responded to prostate-derived antigen in vivo (Figure 2a (i) (ii), and b). However, TGF $\beta$-insensitive OT-I T cells found within the draining lymph nodes had proliferated more vigorously ( $\mathrm{PI}=2.8 \pm 0.12 \mathrm{SEM}$ ) than conventional OT-I cells $(\mathrm{PI}=1.6 \pm 0.12 \mathrm{SEM}), 4$ days post-adoptive transfer (Figure $2 \mathrm{~b}$ ). Specific antigen was required for proliferation of OT-I T cells because neither TGF $\beta$-insensitive nor normal OT-I T cells proliferated in syngeneic B6 mice (PI $=1$; Figure 2a (iii)).

As the capacity to respond to TGF $\beta$ retarded both antigenspecific proliferative responses (in vitro and in vivo) and IFN $\gamma$ expression (in vitro) in $\mathrm{CD}^{+} \mathrm{T}$ cells, we next wished to ascertain whether $\mathrm{CD} 8{ }^{+}$T-cell resistance to TGF $\beta$ signaling would cause antigen-dependent pathology in the prostate gland. Naive TGF $\beta$-insensitive or normal OT-I T cells were adoptively transferred into recipient POET or B6 mice. Flow cytometric analysis of single cell suspensions obtained from disaggregated prostate tissue removed 5 days later, indicated that only a very minor population of prostatic cells from POET mice were naive TGF $\beta$-insensitive OT-I T cells $(\sim 0.5 \%)$ compared with almost negligible cells found within control B6 recipient mice, or POET or B6 mice transferred with normal naive OT-I T cells (Figure 2c, black bars). This suggested that naive OT-I T cells could not access the prostate gland, regardless of their TGF $\beta$-response potential. In contrast, naive TGF $\beta$-insensitive or normal OT-I T cells, which had been activated in vitro before adoptive transfer into recipient mice, were found in significantly greater numbers within the prostate tissue of POET mice as compared to the prostates of control B6 mice (Figure 2c, white bars), with a significantly larger proportion of in vitro

Figure 2 TGF $\beta$-insensitive OT-I T cells proliferate in vivo in response to cognate antigen recognition and induce severe prostatic inflammation if activated before transfer. Single cell suspensions of pooled lymph nodes from dnTGFRIIxOT-I or OT-I mice were CFSE labeled and adoptively transferred to POET recipient mice. At 2, 3 and 4 days post-transfer, single cell suspensions were made from the prostate-draining lymph nodes, stained with anti-CD8 antibody

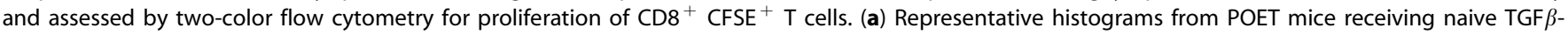
insensitive (i) or normal (ii) OT-I T cells, with control B6 recipient shown in (iii). (b) The proliferative index was determined using WEASEL version 2 software analysis with mean \pm SEM shown. ${ }^{\star} P<0.1 ;{ }^{*} P<0.01$. In (c), pooled lymph node cells from donor mice harboring naive TGF $\beta$-insensitive or TGF $\beta$-sensitive OVA-specific CD8 ${ }^{+}$T cells were adoptively transferred into B6 and POET recipients (10 ${ }^{7}$ i.v.; black bars) or incubated in vitro with SIINFEKL-pulsed B6 splenocytes for 4 days to generate activated OVA-specific T cells before adoptive transfer ( $10^{7}$ i.v.; white bars). After 5 days, prostates were removed and disaggregated with resultant cells analyzed by flow cytometry for the presence of OT-I cells by anti-CD8 and anti-V $\beta 55.1 / 5.2 \mathrm{~T}$-cell staining. In (d), representative histologic features (H\&E staining) of ventral prostate sections taken from animals 10 days after adoptive transfer of in vitro-activated OT-I T cells ( $\times 20$ magnification). Arrows indicate inflammatory cell infiltrate, with arrowheads indicating dead or dying epithelial cells and necrotic cell debris. Inset, enhanced magnification $(\times 40)$ with arrowhead indicating a cell with condensed chromatin. 
activated TGF $\beta$-insensitive OT-I cells found within the POET prostate as compared to normal in vitro activated OT-I cells.
To determine whether this increase in activated OT-I $\mathrm{T}$ cells found within the prostate of POET mice could elicit prostate pathology, POET or B6 mice received in vitro

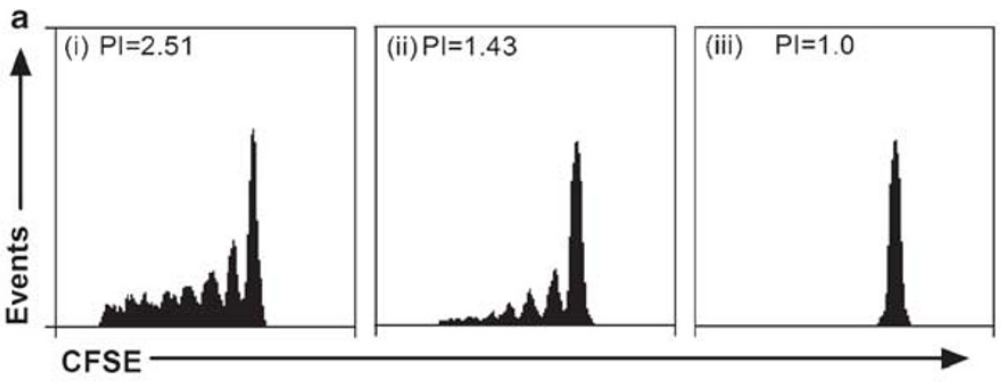

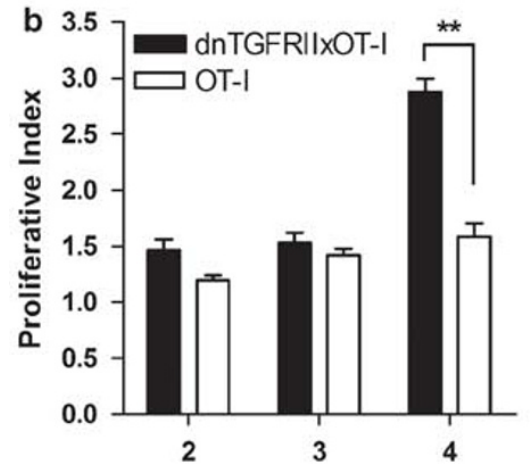

Days post adoptive transfer

d
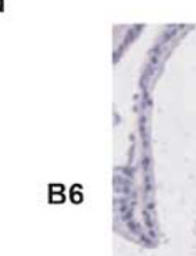

POET

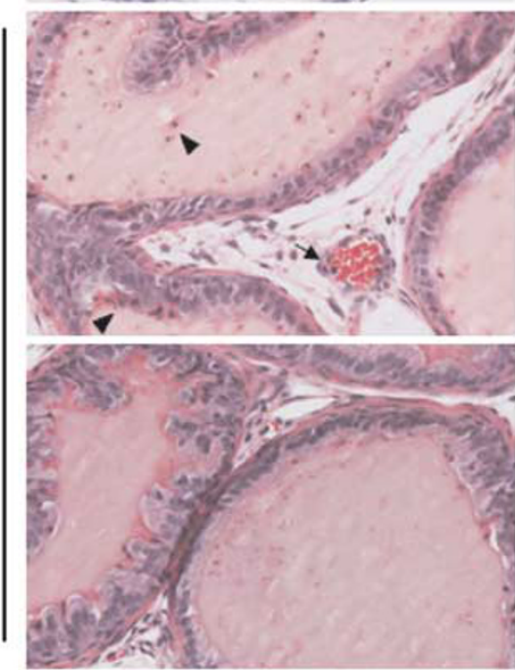

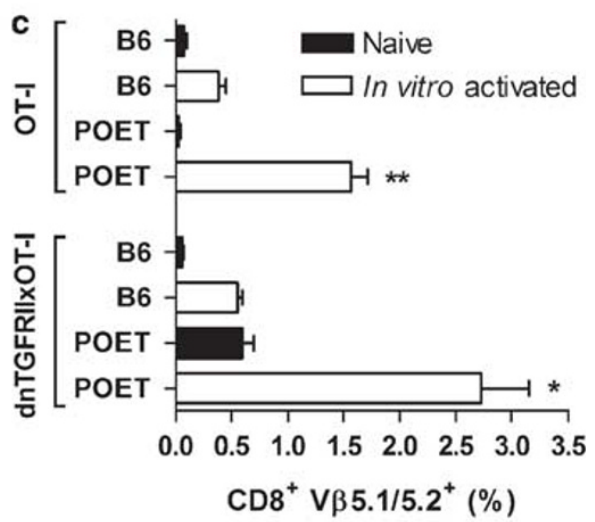

dnTGFRIIXOT-I

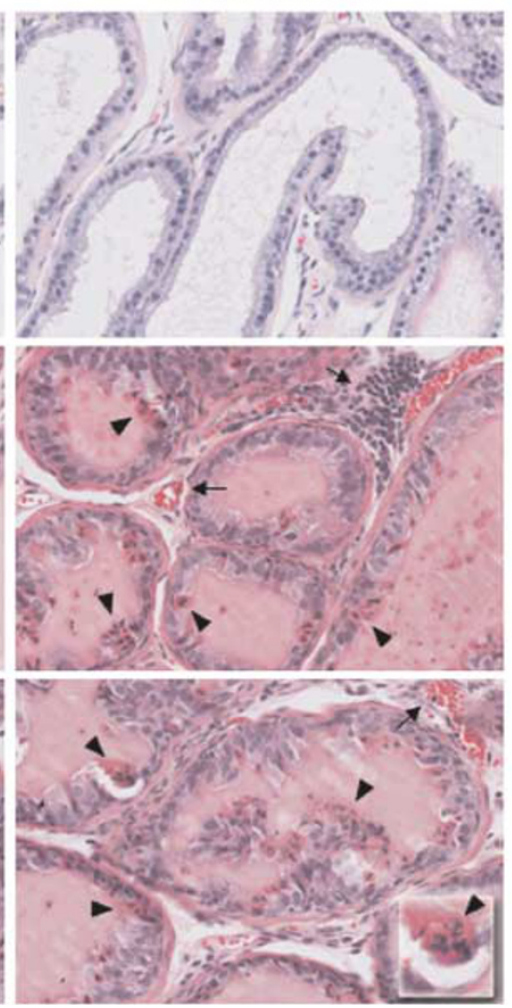


activated TGF $\beta$-insensitive or normal OT-I T cells and 10 days later, prostates were removed and evaluated histologically for evidence of elicited prostatic pathology (Figure 2d). A more prominent inflammatory cell infiltrate was evident in prostate tissue sections taken from POET mice, which received activated TGF $\beta$-insensitive OT-I T cells, as compared to mice receiving control OT-I cells (Figure 2d, arrows). These changes were dependent on OVA antigen expression, as no infiltrate was observed in the prostates of B6 control mice (Figure 2d, top row). Although necrotic cellular debris was observed in lumens of prostatic acini of POET mice receiving either TGF $\beta$-sensitive or -insensitive OT-I T cells, $\mathrm{CD}^{+}$ T-cell resistance to TGF $\beta$ signaling was more evidently associated with intraluminal dead or dying epithelial cells (Figure 2d, arrowheads). This cellular death may have occurred by apoptotic mechanisms, as many dying cells exhibited chromatin condensation (Figure 2d, inset, arrowhead).

\section{Deregulated TGF $\beta$-Signaling in the Endogenous T-cell Population Inhibited Early Tumor Progression in Transgenic Adenocarcinoma of Mouse Prostate Mice}

The results of previous experiments suggested that an autoimmune reaction to prostate-specific self-antigen (OVA in our model) may be induced; however, prior activation of these prostate antigen-specific $\mathrm{T}$ cells would be required. Moreover, tissue damage was more extensive if these T cells were rendered insensitive to the effects of TGF $\beta$ signaling. Although these effects were observed in the T-cell adoptive transfer model, a model in which OVA expression within the prostate at puberty induces peripheral tolerance, an event after which a large precursor frequency of antigen-specific transgenic cells are transferred, we wished to determine if these effects could be reproduced in a more clinically relevant setting with a physiological number of TGF $\beta$-insensitive T cells present at the initiation of peripheral tolerance to a prostate tumor antigen. To this end, the T-cell-specific TFG $\beta$ insensitive mice were bred with TRAMP mice to generate offspring in which the endogenous T-cell population would be insensitive to TGF $\beta$-mediated signaling, while at the same time these mice retained the capacity to develop spontaneous prostate tumors. TRAMP mice with different TGF $\beta$ T-cell response potentials were established and prostate tumorigenesis monitored over a period of 30 weeks. At various matched ages, the prostates from experimental and littermate control mice were sampled and assessed histologically for the initiation and progression of prostate tumors. Results indicated that while some TGF $\beta$-insensitive TRAMP mice showed evidence of adenocarcinoma (grade 5), $80 \%$ of prostate samples were found to have normal epithelium (Figure 3a) or only low-level PIN (grade 2) with little change observed over 30 weeks. In contrast, all age-matched control TRAMP mice exhibited some degree of neoplastic change, with most (77\%) at a grade 3 level (Figure 3b) or above.
Early during prostate cancer progression, at 15-20 weeks of age, TGF $\beta$-insensitive TRAMP mice had a significantly lower mean prostatic score of $1.5( \pm 0.24$ SEM) than agematched littermate control TRAMP mice $(2.8 \pm 0.2$ SEM; Figure 3c). Subsequently, however, at 21-25 weeks of age, the mean scores for TGF $\beta$-insensitive and control TRAMP mice were similar at $3.13( \pm 0.97 \mathrm{SEM})$ and $3.83( \pm 0.54$ SEM $)$, respectively. To determine whether this difference in prostate score observed in early tumor formation could be linked to changes in inflammatory infiltrate within the prostate tissue of TRAMP mice, prostate tissue samples taken from mice with a prostate score of 2 were stained with anti-CD3 to elucidate any changes in T-cell infiltrate. As indicated in Figure 3d, more CD3-positive cells were evident within the prostates of TGF $\beta$-insensitive TRAMP mice as compared to pathology score and age-matched control TRAMP mice (Figure 3e).

\section{DISCUSSION}

By generating antigen-specific $\mathrm{T}$ cells that were insensitive to the effects of TGF $\beta$, the potential tolerogenic effect that TGF $\beta$ signaling has on $\mathrm{CD}^{+} \mathrm{T}$ cells may be explored. We examined the differential effects that TGF $\beta$ signaling had on antigen stimulation of TGF $\beta$-insensitive or TGF $\beta$-sensitive OVA-specific $\mathrm{CD}^{+}{ }^{+} \mathrm{T}$ cells. TGF $\beta$-insensitive T cells proliferated to a greater extent than control $\mathrm{T}$ cells, and a greater proportion of TGF $\beta$-insensitive $\mathrm{CD}^{+}{ }^{+} \mathrm{T}$ cells produced IFN $\tilde{a}$. These results are consistent with other reports in which nonspecific stimulation of splenocytes from dnTGFRII transgenic mice in vitro results in higher IFN $\gamma$ production, which correlated with enhanced effector function in vivo. ${ }^{38}$ Similarly, ex vivo-expanded tumor-antigen-specific TGF $\beta$ insensitive $\mathrm{CD}^{+}{ }^{+} \mathrm{T}$ cells, when adoptively transferred into recipient mice with established pulmonary tumors, were able to contain tumor growth and limit tumor metastasis; an effect which correlated with elevated IFNã serum concentrations. ${ }^{39}$ These findings, along with the lymphoproliferative disorders observed in mice deficient in TGF $\beta 1^{15,40}$ or in mice with $\mathrm{CD} 8{ }^{+} \mathrm{T}$ cells-expressing dnTGFRII, ${ }^{41}$ confirm the role that TGF $\beta$ signaling has in controlling T-cell proliferation, thus maintaining T-cell homeostasis.

Although naive TGF $\beta$-insensitive T cells proliferated more vigorously after interaction with cognate antigen in vitro, $\mathrm{CD} 8{ }^{+}$T-cell resistance to TGF $\beta$ signaling was not sufficient to enable antigen-specific $\mathrm{CD}^{+} \mathrm{T}$ cell to infiltrate OVA-expressing prostate tissue. Nevertheless, fully activated $\mathrm{T}$ cells, regardless of TGF $\beta$ sensitivity, were able to infiltrate the POET prostate gland but only TGF $\beta$-insensitive $\mathrm{CD} 8^{+}$ $\mathrm{T}$ cells were associated with significant prostate tissue damage. Transforming growth factor- $\beta$-mediated suppression of effector function within tissues was seen in other adoptive transfer models using activated antigen-specific $\mathrm{CD}^{+}$ $\mathrm{T}$ cells. In vivo primed but ex vivo-expanded $\mathrm{T}$ cells were transferred into hosts with established tumors and partially controlled tumor growth regardless of the interval between 

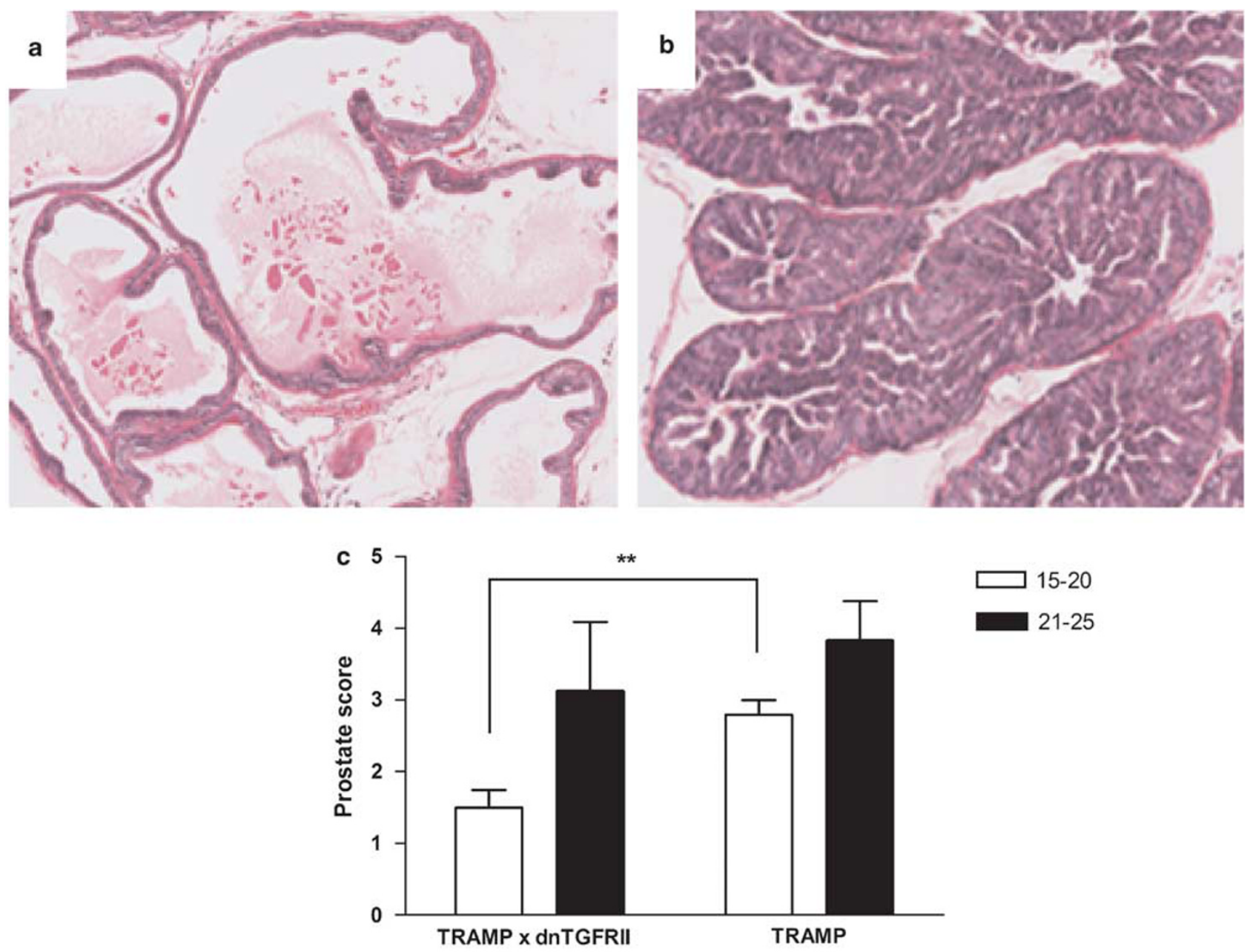

15-20

$21-25$
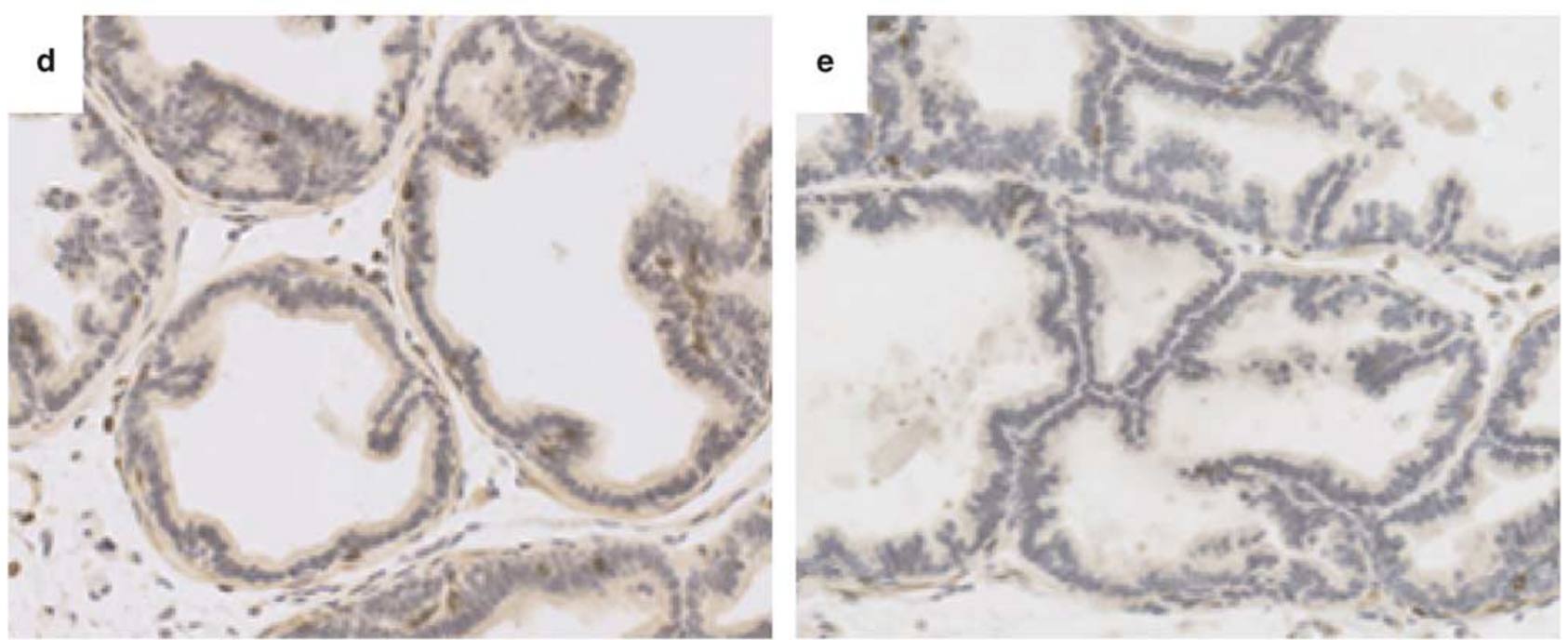

Figure 3 TRAMP $\times$ dnTGFRII mice exhibit delayed spontaneous tumor formation. Groups of TGF $\beta$-insensitive and control TRAMP mice were generated, and followed for the formation of prostate tumors. Ventral prostate lobes were removed at various times over 30 weeks, processed and sectioned $(5 \mu \mathrm{M})$ for the presence of CD3 as well as H\&E staining and histologic analysis. (a) Representative sections of prostates are shown taken at 17 weeks of age, TGF $\beta$ insensitive TRAMP mice showing normal epithelium (prostate score $=1$ ) and $(\mathbf{b})$, control TRAMP mice with prostate showing high-grade PIN (prostate score $=3$ ). Mean prostate scores of at least 10 mice per group are shown in (c) with error bars \pm SEM and $P<0.01$. Representative ventral prostate sections taken from TGF $\beta$-insensitive (d) and control (e) TRAMP mice exhibiting a prostate score $=2$ where assessed for the presence of T-cell infiltrate by anti-CD3 staining, followed by detection with DAB to identify positive cells (dark staining). 
tumor engraftment and adoptive immunotherapy. However, if these $\mathrm{T}$ cells were engineered to express dnTGFRII then most of the tumors were eradicated. ${ }^{39}$ Similarly, established syngeneic lymphomas and melanomas regressed in Rag-/- mice that had been reconstituted with TGF $\beta$-insensitive $\mathrm{CD}^{+}{ }^{+} \mathrm{T}$ cells. Tumor eradication depended on $\mathrm{CD} 4^{+} \mathrm{T}$ cells, and in contrast to the previous study, ${ }^{39}$ tumors were only eradicated completely when $\mathrm{T}$ cells were transferred no later than 3 days after tumor inoculation. ${ }^{42}$ An effective antitumor response in this tumor model required $\mathrm{CD}_{4}^{+} \mathrm{T}$ cell help to prime cytotoxic $\mathrm{T}$ lymphocytes (CTL) and sufficient time for effector CTL to exert tumor control. Similarly, radiation bone-marrow chimera mice, which were reconstituted with TGF $\beta$-insensitive bone marrow and then challenged with melanoma or prostate cancer cell lines, exhibited 70 or $80 \%$ rates of inhibition of tumor engraftment, respectively, which were shown to depend in part on an effective CTL response. ${ }^{43}$

These data indicate that mice harboring TGF $\beta$-resistant effector T cells can defend themselves against the growth of transplanted TGF $\beta$-producing tumor cell lines. However, the rapid growth of transplantable tumors does not adequately mimic the clinical reality of spontaneous tumor formation. The inoculation of a large burden of tumor antigens may overwhelm the immune system and prevent the establishment of peripheral tolerance in which TGF $\beta$ would normally play a part. ${ }^{16}$ This effect together with dysregulated T-cell proliferation resulting from insensitivity to TGF $\beta$ signaling may explain the observed elimination or failure of engraftment of tumor cells in mice harboring $\operatorname{TGF} \beta$-resistant effector T cells.

In the TRAMP model of autochthonous prostate tumorigenesis, tumor growth develops much more slowly than with engrafted tumors. In this model, immunological tolerance to tumor-specific antigens was induced early during tumor development even when very low amounts of previously unseen antigen were expressed. ${ }^{44,45}$ The effects of this control were manifest after adoptive transfer of $\mathrm{CD} 8^{+}$ $\mathrm{T}$ cells, which were specific for the large $\mathrm{T}$ antigen (Tag) oncogene of TRAMP mice. Tag-specific $\mathrm{T}$ cells were rendered tolerant to the Tag itself, and required further stimulation with activated, peptide-pulsed DC before full CTL effector function was restored. Nonetheless, despite intratumoral persistence and initial tumor growth control, the cytolytic activity of the Tag-specific CTL waned to a state of tolerance within 2 weeks by an unknown mechanism. $^{10}$

Here, by crossing dnTGFRII mice with TRAMP mice to generate mice in which prostate cancers developed in the presence of T cells insensitive to the effects of TGF $\beta$ secretion, we provide data in further support of other genetic evidence for T-cell-mediated surveillance of malignant change. ${ }^{46}$ The mechanism underlying our observation is not clear; however, TGF $\beta$ is identified as an important element in the immune control of early tumor progression in an autochthonous prostate cancer model, which more closely resembles human tumor progression than heterotopic or orthotopic transplantable tumor models.

\section{ACKNOWLEDGEMENT}

This study was supported by NHMRC project Grant no. 250318.

1. Jemal A, Siegel R, Ward E, et al. Cancer statistics, 2006. CA Cancer J Clin 2006;56:106-130.

2. Basler M, Groettrup M. Advances in prostate cancer immunotherapies. Drugs Aging 2007;24:197-221.

3. Vieweg J, Dannull J. Technology insight: vaccine therapy for prostate cancer. Nat Clin Pract Urol 2005;2:44-51.

4. Patel PH, Kockler DR. Sipuleucel-T: a vaccine for metastatic, asymptomatic, androgen-independent prostate cancer. Ann Pharmacother 2008:42:91-98.

5. Small EJ, Schellhammer PF, Higano CS, et al. Placebo-controlled phase III trial of immunologic therapy with sipuleucel-T (APC8015) in patients with metastatic, asymptomatic hormone refractory prostate cancer. J Clin Oncol 2006;24:3089-3094.

6. Kiessling R, Wasserman $\mathrm{K}$, Horiguchi $\mathrm{S}$, et al. Tumor-induced immune dysfunction. Cancer Immunol Immunother 1999;48:353-362.

7. Pawelec G. Tumour escape: antitumour effectors too much of a good thing? Cancer Immunol Immunother 2004;53:262-274.

8. Ahmad M, Rees RC, Ali SA. Escape from immunotherapy: possible mechanisms that influence tumor regression/progression. Cancer Immunol Immunother 2004;53:844-854.

9. Lees JR, Charbonneau B, Hayball JD, et al. T-cell recognition of a prostate specific antigen is not sufficient to induce prostate tissue destruction. Prostate 2006;66:578-590.

10. Anderson MJ, Shafer-Weaver K, Greenberg NM, et al. Tolerization of tumor-specific $\mathrm{T}$ cells despite efficient initial priming in a primary murine model of prostate cancer. J Immunol 2007;178:1268-1276.

11. Isaacs JT. Antagonistic effect of androgen on prostatic cell death. Prostate 1984;5:545-557.

12. Danielpour D. Transdifferentiation of NRP-152 rat prostatic basal epithelial cells toward a luminal phenotype: regulation by glucocorticoid, insulin-like growth factor-I and transforming growth factor-beta. J Cell Sci 1999;112(Part 2):169-179.

13. Lee C, Sintich SM, Mathews EP, et al. Transforming growth factor-beta in benign and malignant prostate. Prostate 1999;39:285-290.

14. Shull MM, Ormsby I, Kier AB, et al. Targeted disruption of the mouse transforming growth factor-beta 1 gene results in multifocal inflammatory disease. Nature 1992;359:693-699.

15. Kulkarni $A B$, Huh $C G$, Becker $D$, et al. Transforming growth factor beta 1 null mutation in mice causes excessive inflammatory response and early death. Proc Natl Acad Sci USA 1993;90:770-774.

16. Li MO, Wan YY, Sanjabi S, et al. Transforming growth factor-beta regulation of immune responses. Annu Rev Immunol 2006;24:99-146.

17. Derynck R. TGF-beta-receptor-mediated signaling. Trends Biochem Sci 1994;19:548-553.

18. Salm SN, Burger PE, Coetzee $S$, et al. TGF-beta maintains dormancy of prostatic stem cells in the proximal region of ducts. J Cell Biol 2005;170:81-90.

19. Lee HM, Timme TL, Thompson TC. Resistance to lysis by cytotoxic T cells: a dominant effect in metastatic mouse prostate cancer cells. Cancer Res 2000;60:1927-1933.

20. Cardillo MR, Petrangeli E, Perracchio $L$, et al. Transforming growth factor-beta expression in prostate neoplasia. Anal Quant Cytol Histol 2000;22:1-10.

21. Stravodimos K, Constantinides C, Manousakas T, et al. Immunohistochemical expression of transforming growth factor beta 1 and $\mathrm{nm}-23 \mathrm{H} 1$ antioncogene in prostate cancer: divergent correlation with clinicopathological parameters. Anticancer Res 2000;20:3823-3828.

22. Shariat SF, Kattan MW, Traxel E, et al. Association of pre- and postoperative plasma levels of transforming growth factor beta(1) and interleukin 6 and its soluble receptor with prostate cancer progression. Clin Cancer Res 2004;10:1992-1999.

23. Steiner MS, Barrack ER. Transforming growth factor-beta 1 overproduction in prostate cancer: effects on growth in vivo and in vitro. Mol Endocrinol 1992;6:15-25. 
24. Wikstrom $P$, Stattin P, Franck-Lissbrant I, et al. Transforming growth factor beta1 is associated with angiogenesis, metastasis, and poor clinical outcome in prostate cancer. Prostate 1998;37: 19-29.

25. Wikstrom $\mathrm{P}$, Damber J, Bergh A. Role of transforming growth factor-beta1 in prostate cancer. Microsc Res Tech 2001;52 411-419.

26. Kim IY, Ahn HJ, Lang S, et al. Loss of expression of transforming growth factor-beta receptors is associated with poor prognosis in prostate cancer patients. Clin Cancer Res 1998;4:1625-1630.

27. Kim WS, Park C, Jung YS, et al. Reduced transforming growth factorbeta type II receptor (TGF-beta RII) expression in adenocarcinoma of the lung. Anticancer Res 1999;19:301-306.

28. Inge TH, Hoover SK, Susskind BM, et al. Inhibition of tumor-specific cytotoxic T-lymphocyte responses by transforming growth factor beta 1. Cancer Res 1992;52:1386-1392.

29. Matthews $E$, Yang T, Janulis L, et al. Down-regulation of TGF-beta1 production restores immunogenicity in prostate cancer cells. Br J Cancer 2000;83:519-525.

30. Lees JR, Charbonneau B, Swanson AK, et al. Deletion is neither sufficient nor necessary for the induction of peripheral tolerance in mature CD8+ T cells. Immunology 2006;117:248-261.

31. Hogquist KA, Jameson SC, Heath WR, et al. T cell receptor antagonist peptides induce positive selection. Cell 1994;76:17-27.

32. Greenberg NM, DeMayo F, Finegold MJ, et al. Prostate cancer in a transgenic mouse. Proc Natl Acad Sci USA 1995;92: 3439-3443.

33. Gorelik L, Flavell RA. Abrogation of TGFbeta signaling in T cells leads to spontaneous $\mathrm{T}$ cell differentiation and autoimmune disease. Immunity 2000;12:171-181.

34. Lyons $A B$, Parish $C R$. Determination of lymphocyte division by flow cytometry. J Immunol Methods 1994;171:131-137.

35. Diener KR, Moldenhauer LM, Lyons AB, et al. Human Flt-3-ligandmobilized dendritic cells require additional activation to drive effective immune responses. Exp Hematol 2008;36:51-60.
36. Gingrich JR, Barrios RJ, Foster BA, et al. Pathologic progression of autochthonous prostate cancer in the TRAMP model. Prostate Cancer Prostatic Dis 1999;2:70-75.

37. Hurwitz AA, Foster BA, Kwon ED, et al. Combination immunotherapy of primary prostate cancer in a transgenic mouse model using CTLA-4 blockade. Cancer Res 2000;60:2444-2448.

38. Gojova A, Brun V, Esposito B, et al. Specific abrogation of transforming growth factor-beta signaling in $\mathrm{T}$ cells alters atherosclerotic lesion size and composition in mice. Blood 2003;102:4052-4058.

39. Zhang $Q$, Jang $T L$, Yang $X$, et al. Infiltration of tumor-reactive transforming growth factor-beta insensitive CD8+ T cells into the tumor parenchyma is associated with apoptosis and rejection of tumor cells. Prostate 2006;66:235-247.

40. Yaswen $L$, Kulkarni AB, Fredrickson $T$, et al. Autoimmune manifestations in the transforming growth factor-beta 1 knockout mouse. Blood 1996;87:1439-1445.

41. Lucas PJ, Kim SJ, Melby SJ, et al. Disruption of T cell homeostasis in mice expressing a $T$ cell-specific dominant negative transforming growth factor beta II receptor. J Exp Med 2000;191:1187-1196.

42. Gorelik L, Flavell RA. Immune-mediated eradication of tumors through the blockade of transforming growth factor-beta signaling in $T$ cells. Nat Med 2001;7:1118-1122.

43. Shah AH, Tabayoyong WB, Kundu SD, et al. Suppression of tumor metastasis by blockade of transforming growth factor beta signaling in bone marrow cells through a retroviral-mediated gene therapy in mice. Cancer Res 2002;62:7135-7138.

44. Degl'Innocenti $E$, Grioni M, Boni A, et al. Peripheral T cell tolerance occurs early during spontaneous prostate cancer development and can be rescued by dendritic cell immunization. Eur J Immunol 2005;35:66-75.

45. Mihalyo MA, Hagymasi AT, Slaiby AM, et al. Dendritic cells program non-immunogenic prostate-specific $T$ cell responses beginning at early stages of prostate tumorigenesis. Prostate 2007;67:536-546.

46. Dunn GP, Koebel CM, Schreiber RD. Interferons, immunity and cancer immunoediting. Nat Rev Immunol 2006;6:836-848. 